\title{
Eddy covariance based methane flux in Sundarbans mangroves, India
}

\author{
Chandra Shekhar Jha ${ }^{1}$, Suraj Reddy Rodda, ${ }^{2, *}$, Kiran Chand Thumaty ${ }^{1}$, \\ A K RAHA ${ }^{2}$ and V K DADHWAL ${ }^{1}$ \\ ${ }^{1}$ National Remote Sensing Centre (ISRO), Balanagar, Hyderabad 500 037, India. \\ ${ }^{2}$ West Bengal Forest Department, Salt Lake, Kolkata 700 098, India. \\ ${ }^{*}$ Corresponding author. e-mail: surajking123@gmail.com
}

\begin{abstract}
We report the initial results of the methane flux measured using eddy covariance method during summer months from the world's largest mangrove ecosystem, Sundarbans of India. Mangrove ecosystems are known sources for methane $\left(\mathrm{CH}_{4}\right)$ having very high global warming potential. In order to quantify the methane flux in mangroves, an eddy covariance flux tower was recently erected in the largest unpolluted and undisturbed mangrove ecosystem in Sundarbans (India). The tower is equipped with eddy covariance flux tower instruments to continuously measure methane fluxes besides the mass and energy fluxes. This paper presents the preliminary results of methane flux variations during summer months (i.e., April and May 2012) in Sundarbans mangrove ecosystem. The mean concentrations of $\mathrm{CH}_{4}$ emission over the study period was $1682 \pm 956 \mathrm{ppb}$. The measured $\mathrm{CH}_{4}$ fluxes computed from eddy covariance technique showed that the study area acts as a net source for $\mathrm{CH}_{4}$ with daily mean flux of $150.22 \pm 248.87 \mathrm{mg}$ $\mathrm{m}^{-2}$ day $^{-1}$. The methane emission as well as its flux showed very high variability diurnally. Though the environmental conditions controlling methane emission is not yet fully understood, an attempt has been made in the present study to analyse the relationships of methane efflux with tidal activity. This present study is part of Indian Space Research Organisation-Geosphere Biosphere Program (ISRO-GBP) initiative under 'National Carbon Project'.
\end{abstract}

\section{Introduction}

Methane is one of the most important greenhouse gases that account for global warming by absorbing infrared radiation and thereby contributing significantly to global climate change. According to IPCC (2007), methane $\left(\mathrm{CH}_{4}\right)$ is second in importance with a radiative forcing value of $0.48 \mathrm{Wm}^{-2}$ compared to that of carbon dioxide's value of 1.66 $\mathrm{Wm}^{-2}$. Also, global warming potential of methane for 100 years is 25 , which indicates that it traps 25 times more heat than carbon dioxide in 100 years period. It has also been reported that there was a significant increase in the pre-industrial value of atmospheric methane concentration from about 715 to $1732 \mathrm{ppb}$ in early 1990s, and was $1774 \mathrm{ppb}$ in 2005. Due to the increasing trend of atmospheric methane concentration, it is important to quantify the potentials of various ecosystems for their contribution to the atmospheric methane in developing global scale models for greenhouse gas emissions (IPCC 2007).

Natural wetlands, rice paddies, landfills, ruminants and other biogenic sources have contributed more than $70 \%$ to the total annual methane emission (Kreuzwieser et al. 2003). Among the biogenic sources, methane is produced as an intermediate and end product in microbial processes in

Keywords. Eddy covariance; mangrove forests; methane flux; Sundarbans. 
anoxic conditions and mostly occurs in natural wetlands and thus contributes about $20 \%-39 \%$ of the global source strength (IPCC 2007). Mangroves, the most productive terrestrial ecosystem and natural renewable source, which occupy a large fraction of the tropical coastline, are considered to be potential sources of organic matter due to the high rate of nutrient turnover (Robertson et al. 1992). Methane release in mangrove systems is significant with the methanogenesis which occurs in anoxic conditions prevailing due to tidal flooding (Schutz et al. 1990). However, due to limited studies and lack of continuous datasets on $\mathrm{CH}_{4}$ fluxes from tropical mangrove ecosystems, their potential as a source of methane is yet to be determined (Kreuzwieser et al. 2003).

Mangroves are among the most carbon rich forests in tropics, containing an average of $1023 \mathrm{mg}$ $\mathrm{C} \mathrm{ha}^{-1}$ (Daniel et al. 2011). They are complex ecosystems with various species of trees, shrubs, animals, and microbial lives (Lekphet et al. 2005). Due to these complex associations of several environmental factors over mangroves, methane emissions have been uncertain, and thus the reported values over different mangrove systems have a very wide range. From the mangroves along southwestern coast of Puerto Rico the methane emission of about 4-82 $\mathrm{mg} \mathrm{m}^{-2} \mathrm{~d}^{-1}$ was reported (Sotomayor et al. 1994). Methane emission rates in mangrove wetlands in Queensland, Australia range from about 20 to $350 \mu \mathrm{g} \mathrm{m}^{-2} \mathrm{hr}^{-1}$ (Kreuzwieser et al. 2003). Methane values ranging from about 0 to $192 \mathrm{mg} \mathrm{m}^{-2} \mathrm{~d}^{-1}$ are reported from the mangroves in Tanzania (Lyimo et al. 2002). So far limited studies have been carried out in Sundarbans mangrove ecosystem to study carbon fluxes. Purvaja and Ramesh (2001) state that coastal wetlands are potentially significant sources of atmospheric methane with reported methane emissions from different mangrove ecosystems of south India ranging from 47.23 to $324.48 \mathrm{mg} \mathrm{m}^{-2} \mathrm{~d}^{-1}$.

Most of the studies of methane emission over mangroves measured the concentration of methane using closed chamber techniques which are not so accurate for measuring methane fluxes due to their large temporal and spatial variability (Lapitan et al. 1999; Wille et al. 2008). The present study measures the vertical turbulent $\mathrm{CH}_{4}$ flux between atmosphere and canopy interaction using eddy covariance (EC) method at the ecosystem scale. The EC flux towers have the capability to measure fluxes in-situ, continuously, across several hectares of ecosystem and without artifacts. The major advantages of EC method over chambers technique are the following: chambers technique determines the spatial and temporal variability at relatively small areas $\left(\mathrm{cm}^{-2}\right.$ to $\left.\mathrm{m}^{-2}\right)$ whereas eddy covariance methods are used to characterize temporal variability in huge areas (hundreds of $\mathrm{m}^{-2}$ to $\mathrm{km}^{-2}$ ). Also the spatial extent sampled by the chamber is relatively small when compared with the spatial variation of fluxes across the ecosystem (Pavelka et al. 2007). Compared with chambers, the strengths for EC method are especially important for ecosystems where methane transport occurs through bubbles (ebullition), diffusion through soils, and water columns (Baldocchi and Koteen 2012). Also, the concentrations in the chamber can build up to levels where they inhibit the normal emission rate and also closed chambers alter the atmospheric pressure fluctuations normally found at the soil surface (Lapitan et al. 1999).

A recent survey states that measuring continuous methane fluxes using eddy covariance flux towers are done in different ecosystems (namely tundra, wetlands, meadow, rice, mixed forests, grasslands, etc.), but no tower in mangroves has been reported (Baldocchi and Koteen 2012). The present EC flux tower at Sundarbans, India stands as one of the few towers established in mangrove ecosystems across the world, which has the ability to measure both methane and carbon dioxide fluxes continuously. The present study is carried out under the submodule of 'Soil and VegetationAtmosphere Fluxes' of 'National Carbon Project' initiated by 'Indian Space Research Organisation', the major goal of which is to assess the carbon pools, fluxes, and net carbon balance for the terrestrial biomes in India.

The main objective of this paper is to present the diurnal variations of methane flux and their relations with frictional velocity, tidal activity, and soil temperature during summer months (i.e., April and May 2012).

\section{Study area and tower instrumentation}

Sundarbans, also a world heritage site, is the largest mangrove biosphere reserve in the world, spread across West Bengal, India and Bangladesh. The Indian Sundarbans delta is a part of the Ganga-Brahmaputra-Meghna river basin which is geographically situated between $21^{\circ} 31^{\prime}-22^{\circ} 30^{\prime} \mathrm{N}$ latitudes and $88^{\circ} 10^{\prime}-89^{\circ} 51^{\prime} \mathrm{E}$ longitudes at a mean sea level of $7 \mathrm{~m}$ (figure 1). The Sundarbans cover an area about $9000 \mathrm{~km}^{2}$ which is estimated at about $34 \%$ in Indian territory and $66 \%$ in Bangladesh (Naskar et al. 2009). The Sundarbans is generally very humid and receives a lot of precipitation (annual average of $1800 \mathrm{~mm}$ ). It exhibits wide diversity with a variety of tree species, the most dominant tree being Heritiera fomes (locally 'sundari'), from which name Sundarbans is derived. The islands have also been as natural habitats 

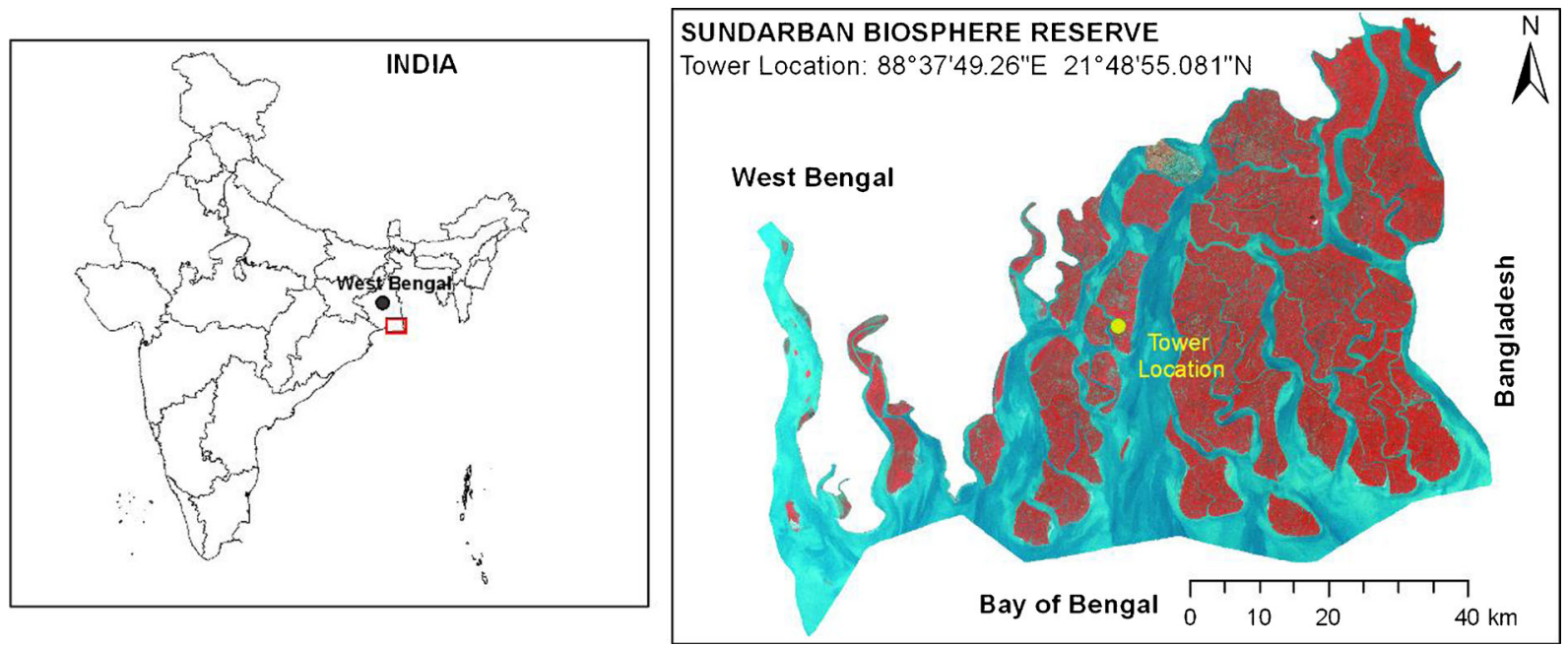

Figure 1. Location of the Sundarbans flux tower on the false colour composite (FCC) of IRS AWIFS data.

for many endangered species including the Royal Bengal tiger.

A tower of $15 \mathrm{~m}$ height has been established at $21^{\circ} 48^{\prime} 55^{\prime \prime} \mathrm{N}$ latitude and $88^{\circ} 37^{\prime} 49^{\prime \prime} \mathrm{E}$ longitude at a mean sea level of $3 \mathrm{~m}$ in an island of the Sundarbans biosphere reserve, India (figure 1). The study area is rich in a variety of mangrove species namely Rhizophora, Avicennia alba and Bruguiera gymnorrhiza with a mean height of $5 \mathrm{~m}$.

Micrometeorological and trace gas $\left(\mathrm{CH}_{4}\right)$ measurements were made at a height of $10 \mathrm{~m}$. A threedimensional sonic anemometer, CSAT-3 (Campbell Sci., USA) was used to measure high frequency wind velocity components (i.e., u, v, w) and speed of sound. The concentrations of methane are measured by infrared gas analyser (IRGA) based on laser absorption spectroscopy at a frequency of $10 \mathrm{~Hz}$. Open path IRGA, LI-7700 (LICOR, USA) is used for measuring concentration of methane. The Sundarbans flux tower site being an uninhabited marshy island with total dependence on solar power, LI-7700 was installed due to its low power demand and low maintenance (Peltola et al. 2012). The measurement range of LI-7700 is between 0 and $25 \mathrm{ppm}$ with an accuracy of $5 \mathrm{ppb}$.

The slow response sensors are also installed on the tower. Wind sensors (Wind Monitor 05103, RM Young, USA) at different levels (2, 4 and $8 \mathrm{~m})$ measure wind speed and wind direction. The micrometeorological parameters like temperature, relative humidity and also radiation components along with soil temperature, and soil heat flux are measured and logged on to the data logger CR3000 (Campbell Scientific Inc.) every 10 minutes.

\section{Methodology}

\subsection{Theoretical considerations for eddy covariance measurements}

Air flow can be imagined as a horizontal flow of numerous rotating eddies. Each eddy has 3D components, including vertical movement of air. Each air parcel has associated features such as temperature, concentration (i.e., $\mathrm{CH}_{4}$, etc.). With the known direction of the movement of these features it can be determined whether the entity of interest is transported into or out of the pool. The basic principle of eddy covariance measurements is that the vertical flux can be calculated as covariance between concentration of the entity of interest (e.g., $\mathrm{CH}_{4}$ ) and vertical wind speed in the eddies. Eddy covariance method assumes that the flow is turbulent and also the terrain is homogenous and flat (Burba and Anderson 2007). During calm and low turbulent nights the fluxes are likely to be underestimated.

\subsection{Flux data processing}

The measured concentrations of $\mathrm{CH}_{4}$ along with high frequency wind velocity components (i.e., $\mathrm{u}$, $\mathrm{v}, \mathrm{w}$ ) and air temperature (which is obtained from speed of sound) and also tower site biometeorological parameters are used to compute fluxes using Eddypro Express post processing software (version 4.1.0, LI-COR, USA, 2012).

The half-hourly processed fluxes are associated with the quality flag, according to the stationary tests and well developed turbulent based flux similarity as proposed by Mauder and Foken (2004). The quality flags 0,1 , and 2 represent data with 
good, moderate and bad values, respectively. The poor quality data (quality flag $=2$ ) and gaps are filled using mean diurnal variation (MDV) method. Though eddy covariance method is the best and most accurate way to measure ecosystem fluxes, $30-40 \%$ of the measurements are replaced with gap-filled values depending on site characteristics
(Moffat et al. 2007; Baldocchi 2008). In the present study, about $40 \%$ of the data was filled using MDV method. MDV is a simple interpolation technique where the missing or low quality value is replaced with the averaged value of the adjacent days at exactly that time of day (Falge et al. 2001). The gap filled data is used and weekly average flux
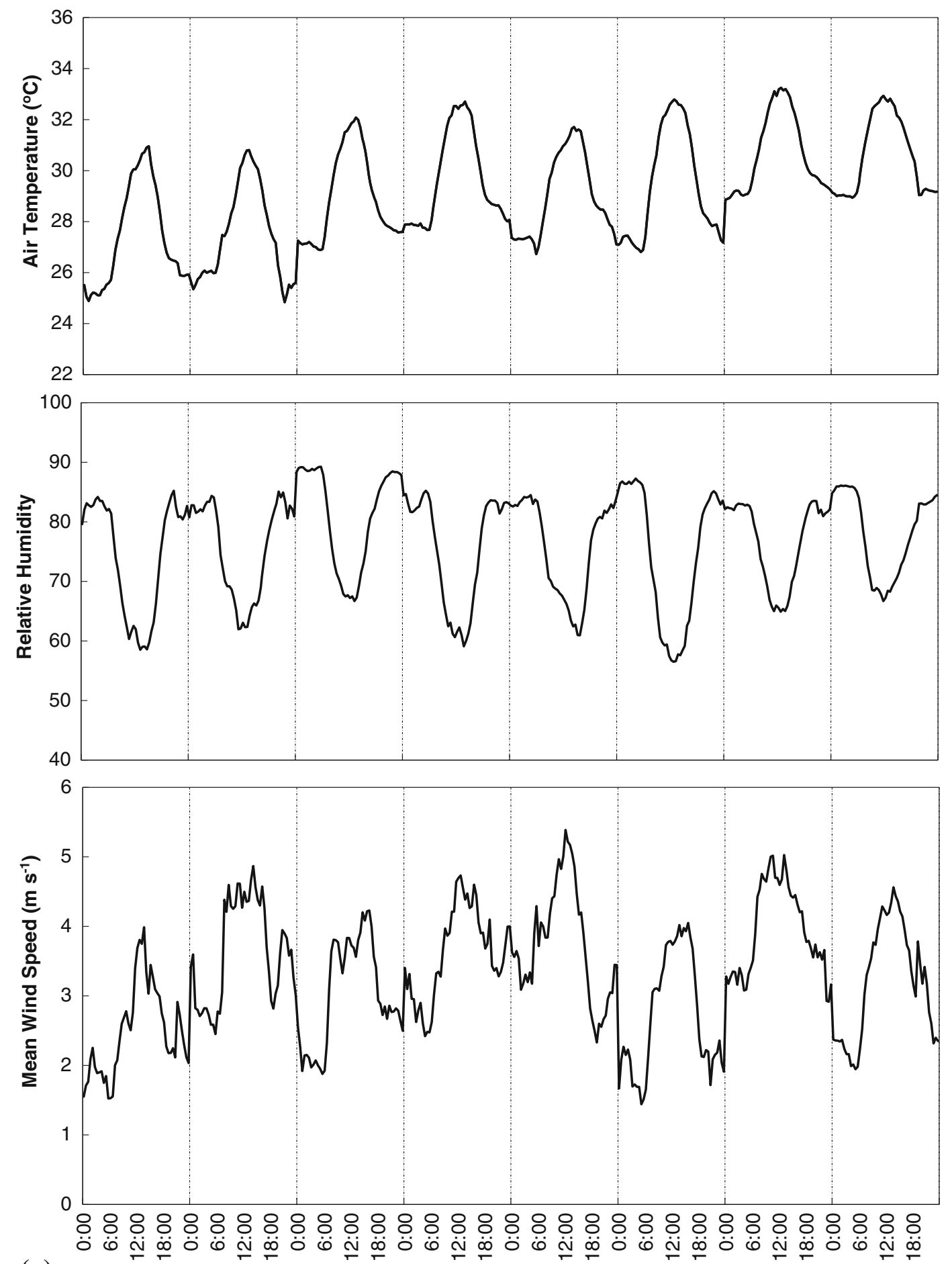

(a)

Figure 2. (a) The weekly average diurnal pattern of air temperature, relative humidity and wind speed during eight weeks of April and May 2012. (b) Predominant wind direction (south-west) during April-May 2012. Wind speed mostly ranged from $2-6 \mathrm{~m} / \mathrm{s}^{-1}$. Orange triangle represents north orientation of eddy flux tower. 


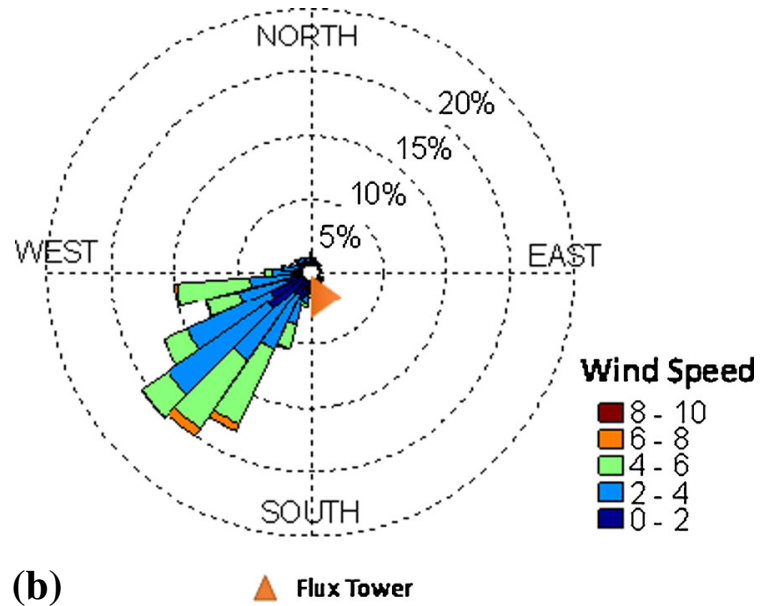

Figure 2. (Continued.)

curves are generated to understand the diurnal variation of methane fluxes.

The flux footprint described as an upwind area 'seen' by the instruments measuring vertical turbulent fluxes has also been estimated using the crosswind integrated footprint model using simple footprint parameterization model by Kljun et al. (2004).

\section{Results and discussions}

The footprint (or fetch) which contributes to the $90 \%$ of the total turbulent flux computations was about $240 \mathrm{~m}$ with a standard deviation of $20 \mathrm{~m}$ during the study period. The study site has recorded a daily average temperature of $29.47 \pm 1.5^{\circ} \mathrm{C}$ and relative humidity of $76.47 \pm 4.15$. Figure 2(a) represents the weekly averaged diurnal pattern of air temperature, relative humidity, and wind speed at a height of $8 \mathrm{~m}$ from the ground. Figure 2(b) shows wind direction and wind speed plotted for the study period over the study site. The predominant wind direction is observed to be south-west during the study period, while the methane sensor (LI-7700) is orientated towards north, thus cancelling any possibility of wind distortion due to tower infrastructure.

Though mangroves are the most carbon rich ecosystems, the methane emissions significantly vary diurnally and their relations with the biophysical parameters are yet to be fully established. During the study period, the average daily methane flux was estimated at $150.22 \pm 248.87 \mathrm{mg}$ $\mathrm{m}^{-2} \mathrm{~d}^{-1}$, showing high variability. These values imply that the study area is a source of methane with varying source strengths. The estimated methane fluxes at Sundarban mangroves are observed to be in range $47.23-324.48 \mathrm{mg} \mathrm{m}^{-2} \mathrm{~d}^{-1}$ with the flux estimates at Pichavaram mangroves of south India (Purvaja and Ramesh 2001). The mean concentration of $\mathrm{CH}_{4}$ during the study period was $1.18 \mathrm{mg} \mathrm{m}^{-3}$ (or $1682 \mathrm{ppb}$ ), similar to the range of the earlier reported methane concentrations (i.e., $0.903 \pm 0.318 \mathrm{mg} \mathrm{m}^{-3}$ ) using gas chromatography in some of the islands in Sundarbans (Mukhophadhya et al. 2001).

The summer months are important since we expect high methane releases due to high temperature and moisture contents. The weekly average diurnal values of methane fluxes varied from -0.5 to $1.5 \mu \mathrm{mol} \mathrm{m} \mathrm{m}^{-2} \mathrm{~s}^{1}$ in the study period (figure 3 ).

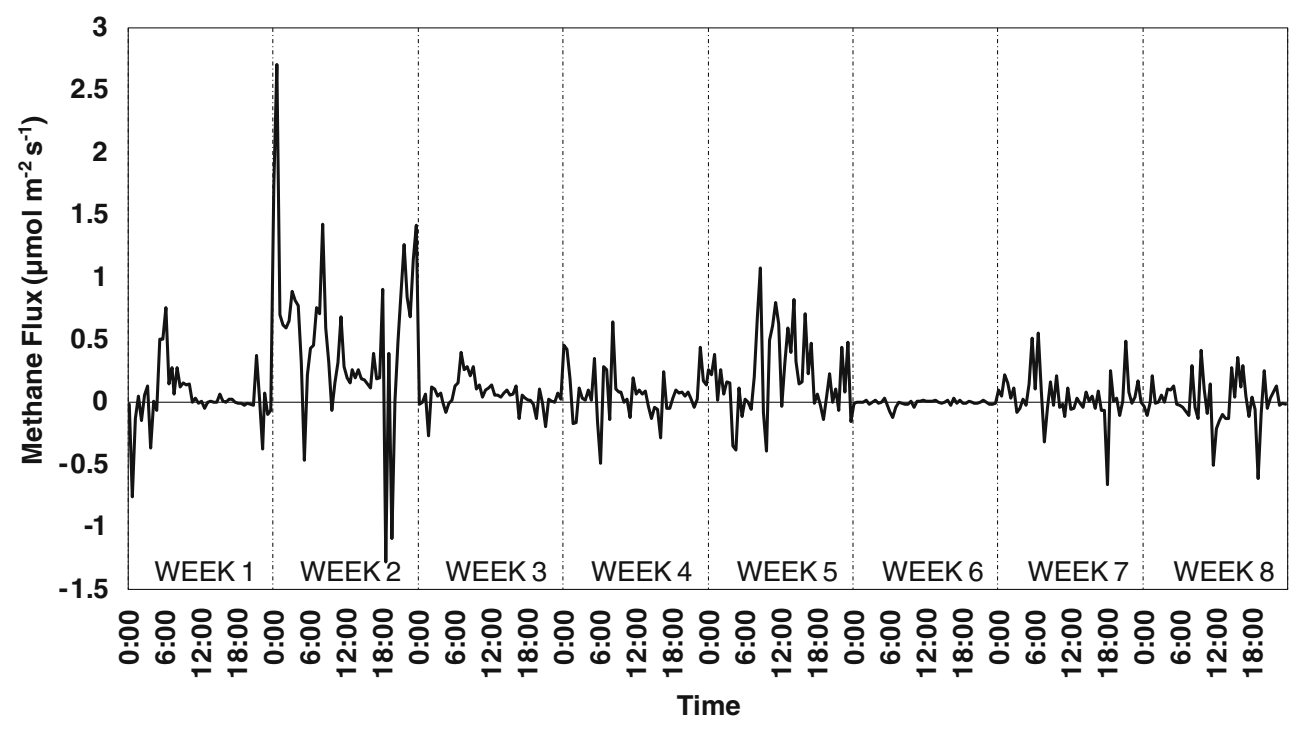

Figure 3. Weekly average diurnal pattern of methane flux observed during eight weeks of the study period. Weeks $1-4$ represent April 2012 and weeks 5-8 represent May 2012. 
Previous studies carried out across Sundarbans mangrove ecosystem measuring methane fluxes using micrometeorological method reported fluxes between 4.53 and $8.88 \mu \mathrm{g} \mathrm{m}^{-2} \mathrm{~s}^{-1}$ (Mukhopadhya et al. 2002).

The data analysis showed the presence of low quality flagged data points that might have resulted due to several environmental conditions not fulfilling the assumptions needed for eddy covariance procedure as mentioned above and for such datasets, gap filling using MDV was carried out. Figure 4 shows the gap filled methane fluxes for representative days (i.e., 17-19 April 2012). In order to model methane fluxes for regional estimate, relations with environmental variables are to be understood. The process of methane production, transport, oxidation, and emission are complex (Abril and Borges 2005) and are hardly established. However, an attempt has been made to understand the variability of methane flux with frictional velocity, soil temperature and tidal activity (Lekphet et al. 2005; Wille et al. 2008). Frictional velocity, the measure of turbulence over the surface which largely depends on wind velocity is found to be directly related to daily methane efflux though with some amount of scatter (figure 5). The methane flux increases with the frictional velocity during the study period.

The correlation of methane flux with tidal activity is not uniform and yet to be established (Lekphet et al. 2003, 2005). The studies carried out in eastern and southern coasts of Thailand showed different relations with high and low tides. The study at eastern coast reported that methane release during high tides was less in comparison with low tides since the process of $\mathrm{CH}_{4}$ transportation from sediments to the atmosphere is hindered by water inundation (Lekphet et al. 2003). The study over Ranong Province, southern coast of Thailand reported that the methane release during low tides was low due to the oxidation state of soil affecting the burrows and cracks (Lekphet et al. 2005). Figure 6 shows methane fluxes with respect to tidal activity for the study area. The tidal charts for the nearest location of the tower (Sagar Island, India) were predicted using 'XTide Tide Prediction Server'. The preliminary results suggested that the integrated methane flux during high tides $\left(5.73 \mathrm{~g} \mathrm{~m}^{-2}\right)$ was found to be about $80 \%$ more than the methane flux during low tides $\left(3.18 \mathrm{~g} \mathrm{~m}^{-2}\right)$ for the study period. This suggests that high methane flux followed high tide. However, more seasonal datasets of methane fluxes over the study area are required to establish relations with tidal activity.

Figure 7 shows the relation between methane fluxes and the soil temperature. The methane

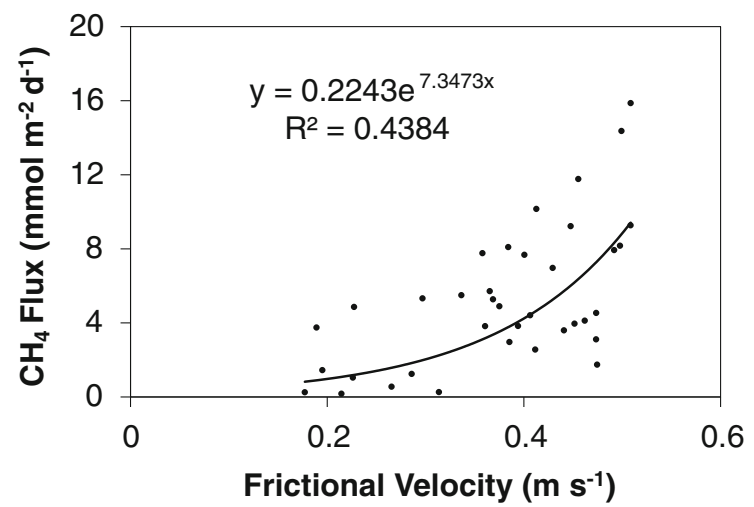

Figure 5. The exponential relation obtained between frictional velocities averaged per day versus the total methane flux per day during the study period.

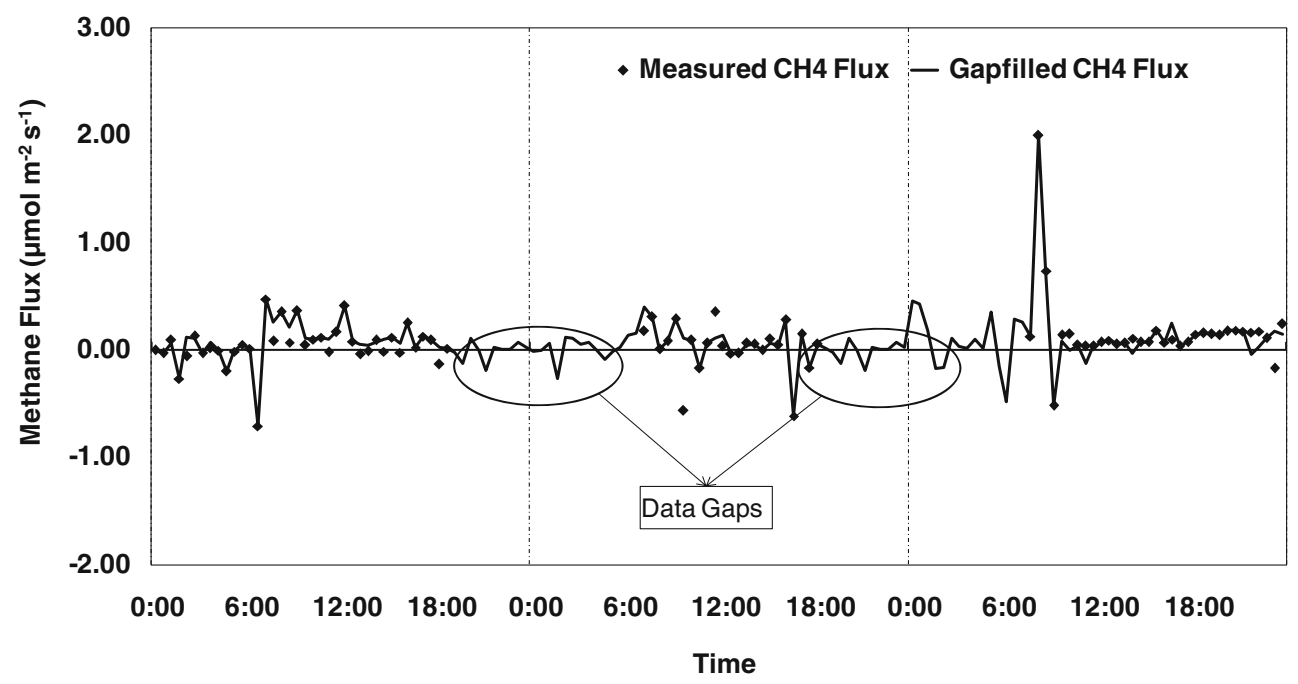

Figure 4. The measured methane flux during 20 to 22 April 2012. Points represent actual measurements. Data gaps are shown in circles. MDV method based gap filled methane flux is represented in line. 


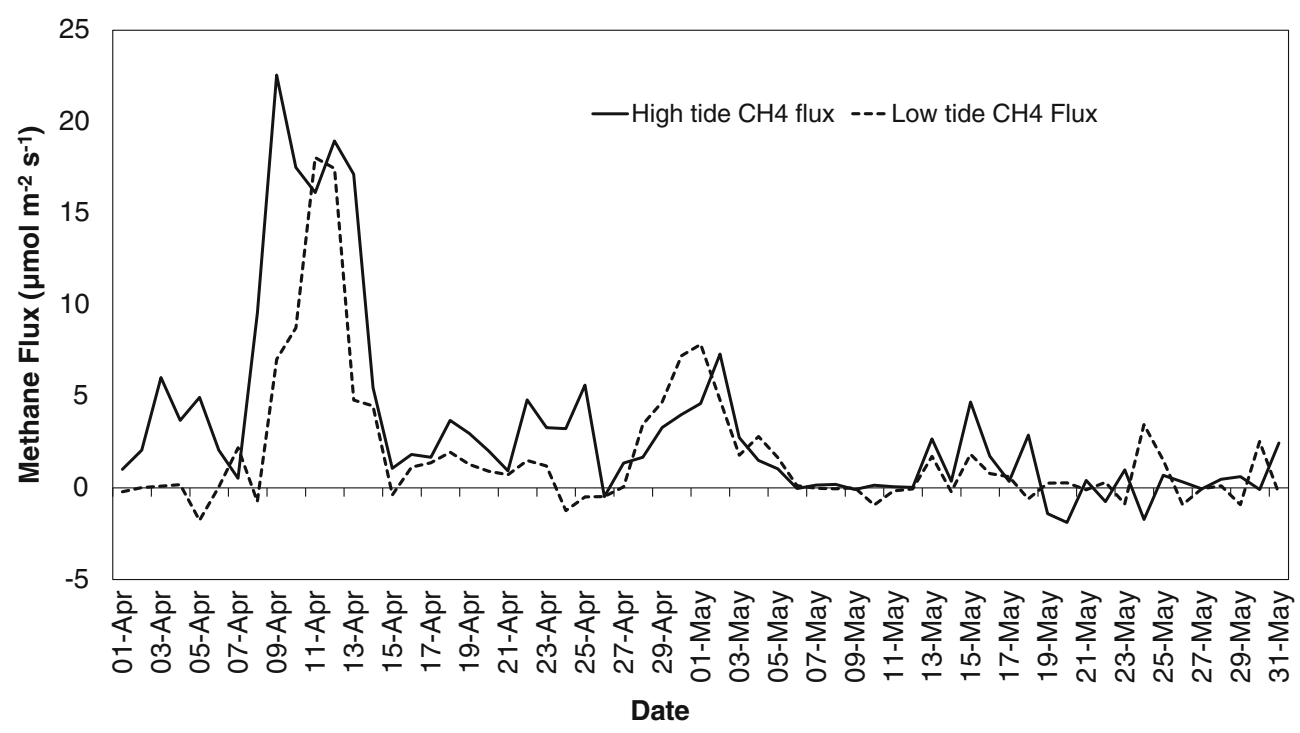

Figure 6. The daily methane flux partitioned into fluxes during high tide and low tide periods for the study period.

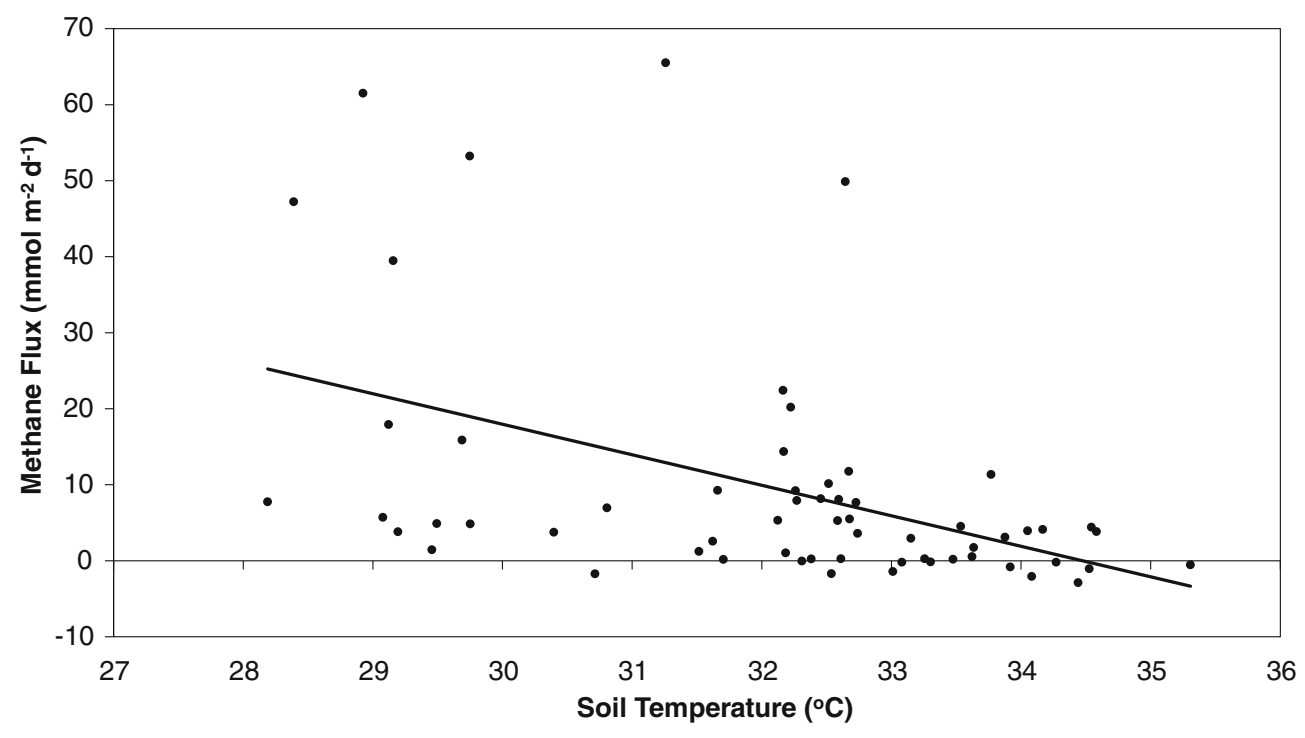

Figure 7. The relationship between total methane fluxes per day versus the averaged soil temperature per day during the study period.

fluxes decreased with increase in soil temperature during the study period with a low correlation coefficient $(r=0.45 ; p<0.001)$.

\section{Conclusion}

The eddy covariance tower establishment in the marshy mangrove has been able to provide uninterrupted data on the environmental parameters as well as the half-hourly computed flux. Due to its high temporal resolution, the diurnal and seasonal variability of the parameters of interest could be quantified with high accuracy and reliability. Though it is known that there is large uncertainty in the methane emission due to the dynamic nature, range, and sources of methane, an attempt has been made to address the environmental control of methane emission with preliminary results from Sundarbans flux tower, which is one of the very few in mangroves across the world. However, long term datasets with continuous monitoring would provide better understanding of interrelationships between $\mathrm{CH}_{4}$ emission with soil temperature and frictional velocity.

\section{Acknowledgements}

This study is funded by Indian Space Research Organisation-Geosphere Biosphere Program (ISROGBP). Authors duly acknowledge the logistic support 
and necessary permissions extended by Director, Joint Director, Ms. Lipika Roy, D.F.O., and Shri A Mandal, Range Forest Officer, Sundarbans Biosphere Reserve. They also acknowledge the useful suggestions of Dr Siyan Ma, University of California at Berkeley.

\section{References}

Abril G and Borges A V 2005 Carbon dioxide and methane emissions from estuaries; In: Greenhouse Gas Emissions - Fluxes and Processes; Springer, pp. 187-207.

Baldocchi D 2008 Turner Review No. 15. 'Breathing' of the terrestrial biosphere: lessons learned from a global network of carbon dioxide flux measurement systems; Aust. J. Bot. 56(1) 1-26.

Baldocchi D and Koteen L 2012 Methane Flux Measurements - New Opportunities for FLUXNET; The newsletter of FLUXNET, Vol. 4(3), January 2012.

Burba G and Anderson D 2007 Introduction to the Eddy Covariance Method: 250 General Guidelines and Conventional Workflow; LI-COR Biosciences, Lincoln, USA.

Daniel C Donato, Boone Kauffman J, Daniel Murdiyarso, Sofyan Kurnianto, Melanie Stidham and Markku Kanninen 2011 Mangroves among the most carbon-rich forests in the tropics; Nat. Geosci. 4 293-297.

Falge E, Baldocchi D and Olson R J et al. 2001 Gap filling strategies for defensible annual sums of net ecosystem exchange; J. Agric. For. Meteorol. 107 43-69.

IPCC 2007 Climate Change: The Physical Science Basis; Contribution of Working Group I to the Fourth Assessment Report of the Intergovernmental Panel on Climate Change; Cambridge University Press, Cambridge, UK and New York, USA.

Kljun N, Calanca P, Rotach M W and Schmid H P 2004 A simple parameterisation for flux footprint predictions; Bound.-Layer Meteorol. 112 503-523.

Kreuzwieser J, Buchholz J and Rennenberg H 2003 Emission of methane and nitrous oxide by Australian Mangrove Ecosystems; Plant Biol. 5 423-431.

Lapitan R L, Wanninkhof R and Mosier A R 1999 Methods for stable gas flux determination in aquatic and terrestrial systems; In: Developments in Atmospheric Science (USA: Elsevier) 24 31-66.

Lekphet S, Adsavakulchai S, Towprayoon S, Chidthaisong A and Nitisoravut S 2003 Methane emission from mangrove area in Thailand; Proceedings of the 2nd Regional Conference on Energy Technology towards a Clean Environment, Phuket, Thailand, 5, 18.

Lekphet S, Nitisoravut S and Adsavakulchai S 2005 Estimating methane emissions from mangrove area in Ranong
Province, Thailand; Songklanakarin J. Sci. Technol. 27(1) 153-163.

Lyimo T J, Pol A and Op den Camp H J M 2002 Methane emission, sulfide concentration and redox potential profiles in Mtoni mangrove sediment, Tanzania, western Indian Ocean; J. Mar. Sci. 1(1) 71-80.

Mauder M and Foken T 2004 Documentation and instruction manual of the eddy covariance software package TK2; Universitat Bayreuth, Abt. Mikrometeorologie, 44p.

Moffat A M, Papale D, Reichstein M, Hollinger D Y, Richardson A D, Barr A G, Beckstein C, Braswell B H, Churkina G, Desai A R, Falge E, Gove J H, Heimann M, Hui D, Jarvis A J, Kattge J, Noormets A and Stauch V J 2007 Comprehensive comparison of gap-filling techniques for eddy covariance net carbon fluxes; J. Agric. For. Meteorol. 147 209-232.

Mukhophadhya S K, Biswas H, Das K L, De T K and Jana T K 2001 Diurnal variation of carbon dioxide and methane exchange above Sundarbans mangrove forest, in NW coast of India; Indian J. Mar. Sci. 30 70-74.

Mukhopadhya S K, Biswas H, De T K, Sen B K, Sen S and Jana T K 2002 Impact of Sundarban mangrove biosphere on the carbon dioxide and methane mixing ratios at the NE coast of Bay of Bengal, India; Atmos. Environ. 36(4) 629-638.

Naskar N M, Naskar K R and Talai S 2009 Addition to the list of brackish water zygnemaceae of Sundarbans and its adjoining areas, India Genus Spirogyra Link; Our Nature 7 187-192.

Pavelka M, Sedlák P, Acosta M, Czerný R, Taufarová K and Janouš D 2007 Chamber techniques versus eddy covariance method during nighttime measurements; International Scientific Conference, Slovakia.

Peltola O, Mammarella I, Haapanala S, Burba G and Vesala T 2012 Field intercomparison of four methane gas analyzers suitable for eddy covariance flux measurements; Biogeosci. 10(6) 3749-3765.

Purvaja G R and Ramesh R 2001 Natural and anthropogenic methane emission from coastal wetlands of south India; J. Environ. Manag. 27 547-557.

Robertson A I, Alongi D M and Boto K G 1992 Food chains and carbon fluxes, in tropical mangrove ecosystems; Coast. Estuar. Stud. 41 293-326.

Schutz H, Seiler W and Rennenberg H 1990 Soil and land use related sources and sinks of methane $\left(\mathrm{CH}_{4}\right)$ in the context of global methane budget; Soils and the Greenhouse effect, pp. 269-285.

Sotomayor D, Corredor J E and Morell J M 1994 Methane and emissions from mangrove soil along the southeastern coast of Puerto Rico; Estuaries 17 140-147.

Wille C, Kutzbach L, Sachs T, Wagner D and Pfeiffer E 2008 Methane emission from Siberian arctic polygonal tundra: Eddy covariance measurements and modeling; Glob. Change Biol. 14(6) 1395-1408. 